\title{
Mitologia e cinema: a propagação dos mitos por meio da trilogia clássica Star Wars
}

\author{
Mythology and cinema: the spread of myths through classic Star Wars trilogy
}

\author{
Rafael Jose Bona ${ }^{[a]}$, Leonardo Antonio Pertuzzatti ${ }^{[b]}$
}

[a] Mestre em Educação (FURB), docente de Graduação na área de Linguagem e Produção Audiovisual e Fotografia vinculado à FURB/UNIVALI, Blumenau, SC - Brasil, e-mail: bonafilm@yahoo.com.br

[b] Bacharel em Comunicação Social, Publicidade e Propaganda (UNIVALI), Itajaí, SC - Brasil, e-mail: leonardomarvel@yahoo.com.br

\section{Resumo}

Este trabalho visa a relacionar a Trilogia Clássica de Star Wars, que compreende os filmes Uma Nova Esperança (1977), O Império Contra-Ataca (1980) e O Retorno do Jedi (1983), com diversos temas e arquétipos presentes em mitologias do mundo inteiro e nas mais variadas civilizações passadas, a fim de encontrar pontos em comum que justifiquem a complexidade da trama no cinema, pois estes aspectos psicológicos fazem parte de um subconsciente coletivo. A estrutura narrativa dos filmes e construção de personagens são fortemente calcadas em histórias mitológicas; assim sendo, o universo ficcional de Star Wars foi incorporado naturalmente na cultura pop mundial, tornando-se uma espécie de mitologia do século XXI. O objetivo geral deste estudo é analisar os mitos inspiradores de Star Wars e delinear os arquétipos presentes nos filmes e suas definições clássicas, bem como identificar as adaptações realizadas para o novo cenário inserido.

Palavras-chave: Star Wars. Mitologia. Cinema.

\section{Abstract}

This work aims to relate Star Wars's Classic Trilogy, which includes the films A New Hope (1977), The Empire Strikes Back (1980) and Return of the Jedi (1983), with various themes and archetypes found in mythologies around the world and in a variety of past civilizations, in order to find common ground to justify the complexity of the plot in the film, because these psychological aspects are part of a collective subconscious. The narrative structure of movies and characters are building sidewalks in heavily mythological stories, therefore, the fictional universe of Star Wars was naturally embedded in pop culture world, becoming a kind of mythology of the XXI century. The aim of this study is to analyze the myths in which Star Wars got its inspiration and delineate the archetypes present in the films and their classical definitions, as well as to identify the adjustments made to the new included scenario.

Keywords: Star Wars. Mythology. Movies. 


\section{Introdução}

O intuito desta pesquisa é relacionar a Trilogia Clássica de Star Wars, dirigida pelo cineasta George Lucas, que compreende os filmes Uma Nova Esperança (1977), O Império Contra-Ataca (1980) e O Retorno do Jedi (1983), com diversos temas mitológicos e arquétipos das mais variadas civilizações passadas, a fim de encontrar pontos em comum que justifiquem a complexidade da trama no cinema. Foi escolhida a Trilogia Clássica, pois os personagens são mais claramente representados por arquétipos, assim como a Jornada do Herói, em Uma Nova Esperança, definida por Joseph Campbell, do qual se fará também a análise detalhada. Parte-se dos livros $O$ Herói de Mil Faces (CAMPBELL, 2007a) e O Poderdo Mito (CAMPBELL, 2007b), ambos escritos pelo renomado antropólogo, estudioso e intérprete da mitologia universal, que compara os símbolos atemporais com os símbolos detectados pela psicologia moderna.

A Trilogia Clássica de Star Wars (também conhecida como Guerra nas Estrelas, no Brasil) conta a história do jovem fazendeiro Luke Skywalker, que vive num desolado planeta deserto com seu tio e tia adotivos. Enquanto a guerra civil intergaláctica eclode entre o maligno Império, que é representado pelo perverso Darth Vader, e os rebeldes, que tentam trazer de volta a paz na galáxia, Luke é pego de surpresa no conflito, e de repente sua vida muda completamente. Agora, com a ajuda de um velho sábio Jedi, ele precisa tomar as rédeas do seu próprio destino. Ao atender ao chamado da aventura, ele conhece robôs, alienígenas, piratas espaciais, criaturas pequenas em tamanho, porém muito poderosas, e lugares que nem imaginava existir. Com o tempo, ele descobre que tem habilidades especiais, e mais que isso, descobre que o homem contra quem lutava, Darth Vader, é na verdade seu próprio pai. Agora Luke precisa vencer uma batalha interna para poder cumprir o que todos esperam de um herói: tornar o mundo um lugar melhor.

As hipóteses deste estudo indicam que a Trilogia Clássica de Star Wars tem sua estrutura narrativa e construção de personagens fortemente calcada em histórias mitológicas, correspondendo diretamente a arquétipos comumente presentes em mitos de inúmeras tradições e culturas. Assim sendo, o universo ficcional de Star Wars foi incorporado naturalmente na cultura pop mundial, tornando-se uma espécie de mitologia do século XXI.

O objetivo geral deste estudo é analisar os mitos inspiradores de Star Wars, e os objetivos específicos são delinear os arquétipos presentes nos filmes e suas definições clássicas,bem como também identificar as adaptações realizadas para o novo cenário inserido, ou seja, um conto baseado em mitos que se passa há muito tempo em uma galáxia distante, tendo em foco uma geração vivendo em plena ascensão tecnológica.

A metodologia deste trabalho se baseou numa pesquisa exploratória. Consistiu no levantamento bibliográfico referente ao tema, para, em seguida, se fazer a análise dos filmes.

\section{A mitologia e o herói}

\section{Mitologia}

Por definição (HOUAISS, 2001), mitologia é uma palavra que vem do grego $\mu$ Oodoyía: "mito", do grego antigo $\mu \nu \theta \theta$ (narrativa, relato), e "logia" (estudo), גojía, ou seja, o estudo de narrativas. Mitos são histórias que apresentam fatos naturais, históricos ou filosóficos com forte simbologia, passados de geração a geração por meio de diálogo e/ou manifestações artísticas, baseadas em tradições e lendas criadas para explicar o universo, a criação do mundo, fenômenos naturais, e toda e qualquer outra coisa às quais explicações convencionais não são atribuíveis. Em outras palavras, o mito foi a primeira tentativa do ser humano para explicar a realidade.

De acordo com uma das maiores autoridades mundiais em mitologia, Joseph Campbell ${ }^{1}$ (2007b), tudo aquilo que os seres humanos têm em comum se revela nos mitos.

\footnotetext{
1 Joseph Campbell (1904-1987), considerado um dos maiores especialistas em mitos do mundo, teve mais de 20 livros publicados que influenciaram tanto artistas como estudiosos e estudantes. Alguns de seus livros são clássicos, como O Herói de Mil Faces, obra que o fez famoso na década de 1940, e As Máscaras de Deus. Quando faleceu, trabalhava em um monumental atlas histórico da mitologia mundial, onde unificava os mitos com seu conhecimento espiritual e intelectual. Para Campbell, Mitologia era "uma espécie de 'canção do Universo', tão enraizada no nosso inconsciente coletivo que dançamos ao som dela, mesmo sem o nome da melodia” (MOYERS apud CAMPBELL, 2007b).
} 
Por milênios a mitologia desempenhou o papel de dar ao homem respostas a perguntas fundamentais sobre aspectos que ele não podia compreender. Todavia, no século XVIII, época em que o mundo era dominado pelo racionalismo, empirismo e pensamento científico de Galileu Galilei, Descartes, Pascal, entre vários outros, a mitologia foi severamente condenada, por ser sinônimo de ilusão e superstições. Nesta época estabeleceu-se a doutrina de que o mundo só poderia ser compreendido por meio dos mecanismos da razão.

Entretanto, no início do século XX, o famoso estudioso da psique humana e pai da psicanálise, Sigmund Freud (1856-1939), retomou o tema e explicou a relação dos mitos com a personalidade inerente do homem, alertando sobre a importância desses. Posteriormente, os estudos foram continuados pelo psiquiatra suíço Carl Gustav Jung (18751961), que ao longo de sua vida experimentou sonhos periódicos e visões com notáveis características mitológicas e religiosas, despertando nele interesse por mitos, sonhos, inconsciente e a psicologia da religião.

\section{Arquétipos}

De acordo com o psicólogo suíço Carl Jung, arquétipos são os componentes do chamado inconsciente coletivo. Conforme já foi citado, o inconsciente coletivo seria uma herança psíquica que todo ser humano recebe em sua constituição. De certa forma, é como se ele já tivesse predisposição para a criação de determinados símbolos e características que ele carrega consigo desde o nascimento, e que independem de valores ou experiências que ele venha a adquirir ao longo da vida. Ainda na doutrina de Jung, os arquétipos correspondem às imagens ancestrais e simbólicas materializadas nas lendas e mitos da humanidade, e constituem oinconsciente coletivo que se revela no indivíduo através dos sonhos, delírios e algumas manifestações de arte (CAMPBELL, 2007b).

Jung, e em seguida Joseph Campbell, sugeriram que o inconsciente coletivo é semelhante ao inconsciente pessoal, e que os mitos e os contos de fadas em geral seriam "sonhos" de uma cultura inteira. Desde a publicação de $A$ Interpretação de Sonhos (Die Traumdeutung, no original, 1899), de Freud, tem havido um notório reconhecimento da importância dos sonhos. Mas mesmo antes disso já havia a interpretação de sonhos, como, por exemplo, a pessoa sonhar que morreu e pensar que alguma coisa de ruim iria acontecer com ela na vida real. Segundo Campbell (2007b, p. 42), "o sonho é uma experiência pessoal daquele profundo, escuro fundamento que dá suporte às nossas vidas conscientes, e o mito é o sonho da sociedade. O mito é o sonho público, e o sonho é o mito privado".

O termo "arquétipo" foi primeiramente usado por filósofos neoplatônicos, como Plotino, para designar as ideias como modelos de todas as coisas existentes, segundo a concepção de Platão. Nas filosofias teístas, o termo indica as ideias presentes na mente de Deus. Pela confluência entre neoplatonismo e cristianismo, o conceito de arquétipo foi incorporado à filosofia cristã pelo teólogo e filósofo São Agostinho (séc. 354-430 d.C.), até vir a ser usado academicamente por Carl Jung, na psicologia analítica, para designar a forma imaterial e amorfa à qual os fenômenos psíquicos tendem a se moldar, nas camadas mais profundas na mente. $\mathrm{Ou}$ seja, os modelos inatos que servem de matriz para o desenvolvimento da psique (CAMPBELL, 2007a).

Há arquétipos que correspondem às mais variadas situações, como nascimento, relações entre pais e filhos, casamento, provas de tentação, confronto com a morte, etc. Uma elaboração derivada desses arquétipos povoa todos os grandes sistemas mitológicos e religiosos do mundo. Todavia, de acordo com $\operatorname{Vogler}^{2}$ (2006), em se tratando de personagens, podemos destacar sete tipos básicos. Todos os outros são variações destes sete: o herói, o mentor, o guardião do limiar, o arauto, o camaleão, o pícaro e a sombra. A seguir se fará uma síntese dos sete tipos básicos de arquétipos defendidos por Vogler.

De acordo com Propp (1997), o mito é uma das possíveis origens do conto, e são relatados por meio da narrativa, que parte do discurso em que são expostos fatos que lhe servem de tema.

Os mitos foram uma das primeiras maneiras de contar histórias mais complexas, ou seja, com vários personagens e um esquema de começo, meio e fim, sempre com uma mensagem $\left(\right.$ ethos $\left.^{3}\right)$. Assim sendo, o mito e o conto são essencialmente iguais. Eles não se distinguem por sua forma, mas pela função social, de acordo com Propp (1997), que depende do grau de cultura de determinado povo.

\footnotetext{
2 Baseado no autor Joseph Campbell (2007a).

3 Ética, moral da história narrada, segundo Comparato (2007).
} 
O mito não pode ser formalmente distinguido do conto. O conto e o mito (especialmente os mitos dos povos que permaneceram aquém do estágio de classes) às vezes coincidem-se entre si, a tal ponto que tanto em etnografia como em folclore esses mitos são freqüentemente chamados de contos (PROPP, 2007, p. 16).

\section{Star Wars}

Os filmes Star Wars são compostos por duas trilogias, ou seja, cada uma forma um conjunto de três filmes conectados mas que podem ser vistos tanto como trabalho único quanto como três obras individuais (Quadro 1).

Os acontecimentos de Star Wars ocorrem em galáxia fictícia, em um tempo indeterminado do passado, sendo que cada filme é acompanhado por um pequeno texto de abertura com a intenção de contextualizar essa história para o espectador. Muitas das suas personagens são humanas, que interagem com várias criaturas fantásticas (em suma, alienígenas), de muitos sistemas planetários diferentes. Como já foi explanado anteriormente pelo tema deste trabalho, são utilizados vários elementos mitológicos, como magia, cavaleiros, princesas, piratas, monstros, procurando reinterpretar arquétipos clássicos presentes no nosso subconsciente coletivo.

Outro tema presente nos filmes é a constante guerra civil intergaláctica entre o Império e os Rebeldes, que querem libertar a galáxia das mãos opressoras do impiedoso governo. Esse conflito foi levemente inspirado pelo período histórico da Roma Antiga, em que a República Romana, que durou quase 500 anos (509 a.C.-27 a.C.), foi transformada em um Império. Em Star Wars, a República Galáctica era um modelo de sociedade na qual milhares de civilizações de planetas diferentes mantinham-se organizadas sob a forma de um Senado Galáctico. No Senado, localizado no planeta metrópole Coruscant, representantes de cada civilização ou planeta interagiam entre si, a fim de solucionar problemas de cunho universal. A República governou a galáxia por milhares de anos, criando um governo justo e pacífico. Porém, ao fim, tornou-se corrupta e acabou sendo dissolvida pelo então chanceler Palpatine, em um golpe de Estado, tornando-se assim o imperador. A era do Império durou por apenas algumas décadas, sendo derrubado pelos Rebeldes.

As informações aqui apresentadas foram coletadas durante muitos anos de pesquisa empírica em diversas fontes diferentes, pois este é um tema que sempre chamou a atenção do autor deste trabalho.

Quadro 1 - Saga Star Wars

\begin{tabular}{cl}
\hline Nova Trilogia & Stars - Episódio I: A Ameaça Fantasma (1999) \\
& Star Wars - Episódio II: O Ataque dos Clones (2002) \\
& Star Wars - Episódio III: A Vingança do Sith (2005) \\
\hline Star Wars - Episódio IV : Uma Nova Esperança (1977) \\
Star Wars - Episódio V: O Império Contra Ataca (1980) \\
\hline
\end{tabular}

Fonte: Os autores.

\section{Análise de caso}

\section{Star Wars: o mito da sociedade moderna}

O antropólogo e estudioso de mitologia Joseph Campbell (2007b, p. 98) ressalta que filmes como Star Wars preenchem parte da necessidade de aventura espiritual, pois ele realiza o ciclo da Jornada do Herói perfeitamente. "Não é apenas uma fábula moral, tem a ver com os poderes da vida, e como eles se alteram pela ação do homem". O que ocorre é apenas uma atualização do contexto, mantendo a essência preservada. Os novos mitos estão a serviço das velhas histórias. Nos contos da Idade da Pedra já havia cenas de lutas contra principados e poderes. Hoje em dia, nos nossos modernos mitos 
tecnológicos, ainda estamos lutando, também contra principados e poderes.

Campbell (2007b) ainda diz que Star Wars certamente possui uma perspectiva mitológica válida, pois os filmes encaram o Estado como uma máquina, e fazem a seguinte pergunta: a máquina vai esmagar a humanidade ou vai colocar-se a seu serviço? Pois a humanidade não provém da máquina, mas da terra. Essa dicotomia está presente em diversos mitos modernos.

Na obra O Poder do Mito (2007b), Campbell é entrevistado pelo jornalista norte-americano Bill Moyers. Este conta que certa manhã, a caminho do seu trabalho, após o falecimento de Campbell, parou diante da vitrine de uma locadora de vídeo da sua vizinhança. Um monitor de TV mostrava cenas do filme de George Lucas, Star Wars. Moyers imediatamente relembrou a ocasião em que Campbell e ele tinham visto o filme juntos, no Rancho Skywalker, de Lucas, na Califórnia.

Lucas e Campbell se tornaram bons amigos depois que o cineasta, reconhecendo sua dívida para com o trabalho de Campbell, convidou o pesquisador para assistir à trilogia Star Wars. Campbell regozijouse com os antigos temas e motivos da mitologia que se desdobraram na tela, em poderosas imagens contemporâneas. Nessa visita em particular, tendo se exaltado mais uma vez com os perigos e proezas de Luke Skywalker, Joseph inflou-se de animação enquanto falava de como Lucas "imprimiu a mais nova e mais poderosa rotação" à história clássica do herói (CAMPBELL, 2007b, p. VII).

Na introdução do seu livro, Moyers fala a respeito de Campbell, seus estudos, Star Wars, e mitologia:

"E o que vem a ser isso?", perguntei.

"É o que Goethe disse no Fausto, mas que Lucas expressou em linguagem moderna - a mensagem de que a tecnologia não vai nos salvar. Nossos computadores, nossas ferramentas, nossas máquinas não são suficientes. Temos que confiar em nossa intuição, em nosso verdadeiro ser."

"Isso não é uma afronta à razão?", eu disse. "E não estamos já, por assim dizer, batendo em rápida retirada da razão?”

"Não é disso que trata a jornada do herói. Nãoé para negar a razão. Ao contrário, pela superação das paixões tenebrosas, o herói simboliza nossa capacidade de controlar o selvagem irracional dentro de nós." Em outras oportunidades,
Campbell tinha lamentado nosso fracasso "em admitir, dentro de nós, o enfebrecimento carnal, lúbrico", endêmico à natureza humana. Agora ele estava descrevendo a jornada do herói, não como um ato de coragem, mas como uma vida vivida em termos de autodescoberta, "e Luke Skywalker nunca foi mais racional do que quando encontrou, dentro de si mesmo, as reservas de caráter necessárias para enfrentar seu destino" (CAMPBELL, 2007b, p. VII).

Moyers, nessa mesma entrevista, também comenta:

Depois que meu filho mais novo tinha assistido a StarWars pela décima segunda ou décima terceira vez, perguntei-lhe: "Por que você repete isso tantas vezes?", e ele respondeu: "Pela mesma razão porque você passou toda a sua vida lendoo Velho Testamento". Ele estava em outro mundo mítico (CAMPBELL, 2007b, p. 19).

\section{Os arquétipos}

\section{O herói}

Certamenteo público-alvo de George Lucas quando ele lançou sua saga espacial era o público adolescente. Isso permitiu representar, por meio do personagem principal, o herói Luke Skywalker, a ânsia de todo jovem: separar-se dos pais e sair de casa, a fim de embarcar em uma nova vida repleta de aventuras. Vogler (2006) diz que heróis são símbolos de esperança, transformação, persistência e determinação, que, para alcançar seus objetivos, ultrapassam barreiras e enfrentam dificuldades durante sua jornada.

Campbell (2007b), em referência a StarWars, explica que todo adolescente é um Luke Skywalker, que precisa abandonar seu planeta (sua família) e partir para a conquista do mundo sozinho. O jovem precisa descartar velhos modelos e construir os seus próprios, numa cruzada em direção ao desenvolvimento da sua personalidade, onde terá que lutar heroicamente contra a tentação de permanecer na origem. Aí então pode-se entender o fato de Luke Skywalker ter de enfrentar o mal na figura do próprio pai, Darth Vader. 


\section{O mentor}

$\mathrm{O}$ arquétipo do mentor, de acordo com Vogler (2006), équem lhe dá conselhos e ensina valiosas lições ao herói, que farão com que ele cresça no decorrer da história. Em síntese, o mentor é um guia.

Campbell (2007) costuma classificar o arquétipo do mentor como o "velho sábio". É o caso em Star Wars, onde a figura do mentor aparece nos personagens de Obi-Wan Kenobi (um idoso eremita) e Mestre Yoda (uma pequena criatura verde com mais de 800 anos de idade), que treinam o jovem Luke Skywalker a fim dele se tornar um Cavaleiro Jedi.

Além dos ensinamentos e conselhos, o mentor pode também ser o responsável por dar presentes ao herói na forma de objetos, que serão fundamentais durante sua aventura. Na saga de George Lucas, é Obi-Wan Kenobi quem dá à Luke um sabre-de-luz, uma espécie de espada que apenas os Jedi possuem, a mesma que outrora pertenceu ao seu pai.

O mentor pode ser um herói de uma jornada anterior que, no passado, falhou na sua jornada, mas adquiriu determinada experiência que pode ser útil ao novo herói que ele está guiando. Portanto, ele é uma projeção do que o herói se tornará ao fim de sua aventura. Em Star Wars, Obi-Wan Kenobi era o mestre de Darth Vader, que falhou ao deixar seu aprendiz ser seduzido pelo Lado Negro da Força.

\section{O guardião do limiar}

Os desafios que o herói enfrenta no decorrer da sua jornada são manifestados por meio dos guardiões do limiar, cujo objetivo é criar obstáculos a fim de impedir que o herói continue sua trilha. Eles representam uma versão menor do perigo real que ainda está por vir: o arquétipo sombra, que veremos mais adiante (VOGLER, 2006).

Os asseclas da sombra podem estar ligados a ela por uma relação de poder, ou seja, soldados. Em Star Wars os guardiões do limiar são representados pelos Stormtroopers, que compõem a tropa imperial. São leais e impiedosos homens de combate vestindo armaduras brancas a serviço de Darth Vader e do Império Galáctico.

\section{$\mathrm{O}$ arauto}

O arauto é a personagem que representa o chamado à mudança, levando o herói a se lançar na aventura. Como diz Vogler (2006), o arauto ilustra o desafio ao herói, é aquele que o avisa de que algo está errado e precisa ser consertado. Esse arquétipo comunica ao herói a aproximação de algo diferente do cotidiano, normalmente em forma de ameaça, e então ele precisa tomar a decisão de ignorar a mensagem ou tomar algum tipo de atitude.

Em Star Wars o arauto é personificado na Princesa Leia, quando aparece pela primeira vez para Luke na forma de um holograma, clamando pela ajuda de Obi-Wan Kenobi. Em um primeiro momento Luke recusa o chamado, ao não tomar atitude alguma; entretanto, é forçado a agir quando R2-D2, o robô responsável pela projeção holográfica, foge no intuito de encontrar o verdadeiro destinatário da mensagem.

\section{O camaleão}

A principal característica deste arquétipo é a mudança, como o próprio nome sugere. É representado por uma personagem que, aos olhos do herói e do espectador, apresenta mudança física ou psicológica, de forma que não seja possível possa prever suas ações (VOGLER, 2006).

Exemplos deste arquétipo em Star Wars são a dupla Han Solo e Chewbacca. No início da trama, Han e Chewie não passam de mercenários dispostos a trabalhar apenas por dinheiro, com sangue frio para eliminar qualquer um que se meta no caminho dos dois. As ações heróicas (resgatar a princesa) também são motivadas por fortuna e glória. Porém, ao fim do filme, mesmo após ter recebido a recompensa, a dupla retorna para a batalha a fim de ajudar Luke a concluir sua missão, por uma questão de honra e amizade. Outro exemplo, no filme seguinte, é Lando Calrissian, que se mostra confiável no início, porém trai seus companheiros, para em seguida buscar redenção.

$\mathrm{O}$ arquétipo do camaleão muda seu comportamento para se adequar a determinada situação, o que muitas vezes pode ser perigoso para o herói, que, por não conhecer sua verdadeira natureza, nunca saberá se ele é realmente confiável (VOGLER, 2006).

\section{O pícaro}

Este arquétipo é representado por qualquer personagem cômico. Sua função primária é fazer rir, a fim de trazer alívio após um momento tenso da história. Ele ajuda o herói a acordar para a 
realidade, denunciando o lado ridículo das situações apresentadas (VOGLER, 2006).

Muitas vezes o pícaro tem um modo ingênuo de enxergar as coisas. É o caso da dupla de robôs R2-D2 e C-3PO em Star Wars. Com personalidades inocentes, quase infantis, o comportamento constantemente conflitante entre as duas personagens gera situações divertidas e inusitadas.

\section{A sombra}

O arquétipo da sombra é representado pelo antagonista ou inimigo do herói, e seu objetivo é, geralmente, a morte ou destruição definitiva da sua contraparte. A função principal da sombra é impor desafios ao herói, de modo que ele tenha que se fortalecer para vencê-los (VOGLER, 2006).

"Sombra" tem relação com o escuro, com o lado negro. A escuridão é uma representação simbólica do mal, da desgraça, da perdição e da morte no mundo ocidental. Porisso, normalmente se relaciona vilões à cor negra, como acontece com Darth Vader em Star Wars.

Da mesma forma que o herói, a sombra se torna mais interessante se possuir trejeitos humanos, ou seja, ter defeitos e outras características que a aproximem do espectador. Na saga de Star Wars, o conflito principal não é apenas físico (duelo de sabresde-luz), mas também psicológico (na verdade, Vader é pai de Luke). Existe uma tempestade emocional toda vez que os antagonistas se encontram.

Além de Vader, outra personagem representante desse arquétipo é o imperador, o primeiro na hierarquia galáctica. Ele personifica o maior e real perigo da saga: o mal puro e sem limites.

A seguir, coloca-se resumidamente no Quadro 2 os personagens e os arquétipos representados por eles, de acordo com Vogler (2006).

\section{Considerações finais}

Cada período da história da humanidade tem seus próprios conjuntos de mitos e rituais que definem as regras básicas de comportamento e convívio em sociedade. As histórias, que podem se apresentar sob a forma de mitos, livros, filmes, etc., auxiliam na formação espiritual e social de cada indivíduo e lhe fornecem parâmetros para atuar em grupo.

O estudo da mitologia permitiu estabelecer um paralelo entre a importância desta e a linguagem de cinema utilizada na Trilogia Clássica de Star Wars. A fórmula épica recheada de arquétipos é uma constante nas produções cinematográficas, e recorre ao emprego de temas e conceitos universais aplicados visualmente e no desenrolar da história. A reinterpretação dos arquétipos mitológicos é a base da atemporalidade dos filmes, pois eles focam temáticas com que todos os indivíduos se relacionam, mas ainda assim incorporam conceitos modernos, como relação entre pais e filhos, histórias de amor que persistem contra todas as adversidades, conflitos de interesse em amizades, entre vários outros.

Mitos sempre existiram e sempre existirão na cultura humana, pois o homem precisa deles a fim de expressar seu inconsciente e explicar o inexplicável. Mitos são o alimento da alma, o elemento que concede esperança e força para continuar, uma forma de lidar com os medos e uma maneira de nos entendermos e à nossa realidade.

Nas culturas primitivas, os mitos eram empregados em dolorosos rituais de passagem e comumente narrados pelos anciãos aos mais jovens. $\mathrm{Na}$ cultura ocidental, durante séculos, tais histórias fizeram-se presentes na literatura grega, latina, e na Bíblia. Hoje em dia, em menor escala, ainda são apresentadas, mas levadas pouco a sério pelas novas

Quadro 2 - Arquétipos e personagens

\begin{tabular}{ll}
\hline \multicolumn{1}{c}{ Arquétipo } & \multicolumn{1}{c}{ Personagem } \\
\hline O herói & Luke Skywalker \\
O mentor & Obi-Wan Kenobi / Yoda \\
O guardião do limiar & Stormtroopers \\
O arauto & Princesa Leia \\
O camaleão & Han Solo e Chewbacca / Lando \\
O pícaro & R2-D2 e C-3PO \\
A sombra & Darth Vader / imperador \\
\hline
\end{tabular}

Fonte: Os autores. 
gerações, que têm dificuldade em absorver tais mitologias em sua roupagem tradicional. A questão é que tais histórias fazem falta, pois sem elas persiste $\mathrm{o}$ vazio do conhecimento, algo que pode comprometer o entendimento de fato inéditos em nossas vidas.

Ao ter isso em mente, os filmes Star Wars, de George Lucas, podem ser considerados o exemplo perfeito de mitologia do século XXI. A essência da saga espacial provém justamente dos arquétipos e motivos mitológicos presentes em quase todas as religiões e mitos relevantes da história da humanidade. A narrativa cinematográfica é apenas um veículo que serve para compartilhar experiências sobre o mundo, mensagens sobre crescimento e escolhas, na forma de metáforas carregadas de significados.

Atualmente, o cinema e a televisão são os grandes responsáveis pela criação de mitos. Porém, percebe-se que depois de vários séculos, a estrutura das histórias e a composição de personagens não sofreram alteração. Tais aspectos não mudam, pois são parte da personalidade humana, são elementos básicos do inconsciente coletivo.

Star Wars traz consigo todos os motivos mitológicos que uma história precisa: arquétipos representando as múltiplas facetas do caráter humano e a Jornada do Herói descrita por Joseph Campbell, que simboliza a trajetória de vida, contendo todas as etapas necessárias para a evolução do ser, ao mesmo tempo que ilustra o antigo conflito entre o Bem e o Mal.

Campbell, que era chamado por George Lucas de "meu Yoda" (referência ao Mestre Jedi da saga), ajudou o cineasta, por meio de seus livros e extensos debates, a entremear sua criação com dezenas de elementos de histórias mitológicas criadas pelo homem desde o início da civilização.

Espera-se que esta pesquisa incentive novos estudos sobre os temas mitologia e linguagem de cinema, a fim de buscar novos pontos de vista acerca da relevância da cultura popular.

\section{Referências}

CAMPBELL, J. O herói de mil faces. São Paulo: Pensamento, 2007a.

$2007 \mathrm{~b}$.

O poder do mito. São Paulo: Palas Athena,
COMPARATO, D. Da criação ao roteiro: teoria e prática. Rio de Janeiro: Summus, 2009.

HOUAISS, A. Dicionário Houaiss da língua portuguesa. Rio de Janeiro: Objetiva, 2001.

PODER do Mito. Direção: Bill Moyers. Produção: Cultura Marcas. São Paulo: Log On Editora Multimídia, 2005. 2 DVDs (354 min).

PROPP, V. As raízes históricas do conto maravilhoso. São Paulo: Martins Fontes, 1997.

STAR WARS-Episódio IV: uma nova esperança. Direção: George Lucas. Estados Unidos: Produção Lucasfilm: 1977. 1 DVD (121 min.)

STAR WARS - Episódio V: O império contra-ataca. Direção: George Lucas. Estados Unidos: Produção Lucasfilm: 1980. 1 DVD (124 min.)

STAR WARS - Episódio VI: O Retorno de Jedi. Direção: George Lucas. Estados Unidos: Produção Lucasfilm: 1983. 1 DVD (134 min.)

STAR WARS - Episódio I: A ameaça fantasma. Direção: George Lucas. Estados Unidos: Produção Lucasfilm: 1999. 1 DVD (136 min.).

STAR WARS - Episódio II: O ataque dos clones. Direção: George Lucas. Estados Unidos: Produção Lucasfilm: 2002. 1 DVD (144 min.).

STAR WARS -Episódio III: A vingança dos Sith.Direção: George Lucas. Estados Unidos: Produção Lucasfilm: 2005. 1 DVD (146 min.).

VOGLER, C. A jornada do escritor. São Paulo: Nova Fronteira, 2006.

Recebido: 20/02/2010

Received: 02/20/2010

Aprovado: 28/03/2010

Approved: 03/28/2010 